\title{
DISENTANGLING DEFINING AND DEMONSTRATING: NOTES ON AN. POST. II 3-7
}

\author{
LaUra M. Castelli \\ https:/ / orcid.org/0000-0001-9522-7395 \\ Ludwig-Maximillians-Universität München \\ Department of Philosophy \\ München \\ Germany \\ laura.castelli@1rz.uni-muenchen.de
}

\section{Article info \\ CDD: 185 \\ Keywords \\ Aristotle \\ Demonstration \\ Definition \\ Knowledge \\ Deduction}

Received: 15.09.2019; Accepted: 03.10.2019

DOI: http://dx.doi.org/10.1590/0100-6045.2019.V42N4.LC

\begin{abstract}
In APo II 3-7 Aristotle discusses a series of difficulties concerning definition, deduction, and demonstration. In this paper I focus on two interrelated but distinct questions: firstly, what are exactly the difficulties emerging from or alluded to in the discussion in II 3-7; secondly, whether and in what sense the discussion in II 3-7 can be considered an aporetic discussion with a specific role to play in the development of the argument in $A P o$ II.
\end{abstract}

\section{Preliminary Remarks}

In $A P o$ II 3-7 Aristotle discusses a series of difficulties concerning definition (horismos), deduction (sullogismos) and 
demonstration (apodeixis) ${ }^{1}$ which are then supposed to find a solution in the positive account of the following chapters. The general strategy of presenting aporiai (i.e. problematic knots meant to come loose once the appropriate conceptual or argumentative resources are found) before spelling out his own views is a strategy notoriously common throughout Aristotle's writings. Unlike the discussion of other difficulties in the corpus, however, the difficulties in these chapters are still baffling in several respects. Interpreters mainly emphasize that these chapters look like a rather episodic series of arguments that Aristotle himself would not regard as seriously challenging ${ }^{2}$, and even those who think that II 3-7 do raise some genuine difficulties do not linger on the details of the discussion ${ }^{3}$.

${ }^{1}$ In what follows I use 'definition', 'deduction' and 'demonstration' as translations of the Greek terms indicated in the parentheses. I will say more on each of these three terms in the course of the paper.

${ }^{2}$ Explicitly Ross, p. 614-5, ad 90a37: "The fact that the chapter (as also chs. 4-7) is aporematic implies that it is dialectical, using sometimes arguments that A. could not have thought really convincing". Barnes in his commentary provides a detailed reconstruction of the single arguments in II 3-7, emphasizing their weaknesses and occasionally adding that these should not "distress" us since they are "still part of the preliminary puzzling" (p. 209, ad 91a15 ff.). McKirahan 1992, p. 198, explicitly voices the puzzlement about the function of II 3-7 (which he does not discuss in detail).

${ }^{3}$ Bronstein 2016 pp. 144-147 emphasizes four points, emerging throughout II 3-7, which turn out to be difficulties for the claim that there can be demonstration of the essence of something. These are: 1) that definitions are indemonstrable; 2) that definition and demonstration are different types of things and are of different objects; 3) that a demonstration that proves what something is is doomed to being question-begging; 4) that a demonstration that proves what something is cannot prove that the essence is 
The fact that Aristotle may already envisage a solution to a difficulty at the moment of formulating that difficulty, however, would hardly be a peculiarity of $A P_{0}$ II 3-7. In fact, this could be claimed for most aporiai throughout Aristotle's writings. However, the fact that Aristotle thinks that there is a way to solve a difficulty does not by itself imply that the difficulty itself is not a genuine one or that it bears no philosophical interest. In particular, in many cases Aristotle seems to think that difficulties emerge because one lacks the appropriate conceptual tools to analyse a certain issue. The nature of the conceptual tools may vary, but it is often the case that the solution of a difficulty amounts to the introduction of more or less sophisticated conceptual distinctions, possibly accompanied by the revision of some given terminology. In such cases, Aristotle suggests that the philosophically interesting point in the discussion of a difficulty is precisely the point captured by the conceptual distinction which is used to solve or dispel the difficulty, while the difficulty might well remain a genuine one for those who do not see the point of the distinction. Accordingly, the very fact that Aristotle may have already grasped the distinction(s) which he intends to use in order to solve a difficulty does not deprive the difficulty itself and its solution of philosophical interest. But given that, as readers, we tend to endorse the privileged perspective of those who already know the solution to a given difficulty, it is sometimes hard to see where the difficulty was to start with. I suggest that this is particularly true for APo II 3-7 and my main aim in

something one. Bronstein focuses on 1)-4) (which are, without any doubt, central and crucial) because he thinks that the opening statement in II 8, 93a1-3 (quoted below) sums up the discussion and, therefore, the difficulties raised in II 3-7. While I do not deny the centrality of the issues Bronstein focuses upon, I think there is more to the difficulties in II 3-7 than is emphasized in Bronstein's account as well as in the reconstructions of other interpreters. 
this paper is that of focussing on some details and some problems in the text which are of some consequence in understanding what the difficulties raised in these chapters exactly are and why Aristotle may find some of them worth raising in the first place. More specifically, in what follows I shall suggest some answers to two interrelated but distinct questions: firstly, what are exactly the difficulties emerging from or alluded to in the discussion in II 3-7; secondly, whether and in what sense the discussion in II 3-7 can be considered an aporetic discussion with a specific role to play in the development of the argument in APo II.

As for the first question, I take it that the challenges Aristotle intends to emphasize in II 3-7 are not confined to those usually identified by interpreters in these chapters. In particular, interpreters usually take these chapters as dealing with one fundamental issue, i.e. whether it is possible to deduce or demonstrate a definition ${ }^{4}$. Although this is one (and perhaps even the) fundamental aspect Aristotle considers, I argue that this point belongs to a family of more complex issues which genuinely trouble him. The general focus of the whole discussion is how the ti esti is shown or

${ }^{4}$ See e.g. Ross, p. 613 ad 90a35: "We must now discuss how a definition is proved, and how reduced to demonstration, what definition is and what things are definable". Barnes, in the commentary, p. 207: "B 3 begins the main burden of the book: to what extent, if at all, can definitions be demonstrated? The introductory chapters are aporematic"; on II 4-6 (p. 208): "Despite Aristotle's remark, the puzzles (aporiai) continue until the end of B 7, and their topic is the same as before"; on B 7 (p. 214): "B 3-6 have discussed the question whether definitions can be demonstrated; in B 7 Aristotle first puzzles over the more general question of whether the definer can offer any sort of proof (92a34-b3); then he produces three more arguments against the view that definers can prove what they express (92b4-25); and finally he rejects the thesis that definitions merely say what certain terms mean (92b26-34)". Further references can be found in the next sections of the paper. 
made known, i.e. the issue of characterizing the nature of the procedure (if any) through which we have access to what something is. In this sense, the problem is not so much or not only that of establishing the relation between two formal objects, as it were, i.e. a statement in predicative form (a definition) and a deductive argument of a certain type (a demonstration). Rather, Aristotle is interested in disentangling what we do when we define and when we demonstrate something, respectively. Furthermore, since for Aristotle epistemic faculties and processes are essentially linked to their respective objects in the sense that epistemic faculties and processes are identified with reference to the objects they are of, any obscurity concerning that of which definition, deduction and demonstration are translates into a difficulty concerning what the latter are. In particular, I intend to emphasize that, if we think of defining, deducing and demonstrating as processes marking each some progress in knowledge, there might be an issue in drawing a neat distinction between things or aspects which become clear in the course of those processes and the objects with reference to which those processes are identified strictly speaking (in other words: that of which a definition, rather than a deduction or a demonstration, is). While it may well turn out that Aristotle does have the conceptual resources to disentangle definition and demonstration by specifying, among other things, what it is that each of them is of exactly, I shall argue, by reviewing the cases that Aristotle discusses in II 3-7, that the distinction is all but trivial, both in theory and with reference to some common philosophical practice at Aristotle's time.

As for the second question, I suggest that there might be a relatively precise sense in which II 3-7 build an aporetic discussion within the economy of $A$ Po II. The aporetic nature of the discussion for Aristotle is best appreciated against the backdrop of APo II 1-2. In particular, I take it that the philosophical motivation for discussing the nature 
of defining and the issue of the relationship between defining, deducing and demonstrating in II 3-7 comes from the development of some general and basic ideas introduced in II 1-2: both the enquiry into the ti esti and the enquiry into the dia ti are enquiries into a middle term expressing the cause explaining why a certain property belongs to a certain subject. The enquiry into a middle term, however, is for Aristotle a characteristic (in the Analytics perhaps the characteristic) feature of deductive reasoning. If defining has anything to do with a middle term, one has to clarify whether and to what extent the procedure of defining consists in or in any way embeds one or more deductive moments. If this is not the case, one will have to explain what defining amounts to and how it can be possibly related to middle terms, deducing and demonstrating. In short, I take it that II 3 presents arguments to the effect that defining and demonstrating are distinct and non-overlapping procedures. This result may represent a challenge for the tenet in II 1-2 that the enquiry into the $t i$ esti and the enquiry into the dia ti converge onto the enquiry into a middle term. II 4-6 address possibly controversial cases about the result in II 3 based on the assumption that demonstration is a deductive process: in fact, Aristotle is familiar with a series of argumentative procedures in which deduction is used to obtain or to establish a definition. Cases of entanglement of deductive and definitional procedures discussed in II 4-6, however, all fail to comply with some basic requirement for being a demonstration. This is the reason why the result obtained in II 3 and the problem that it represents for the picture sketched in II 1-2 are still standing when Aristotle gets to II 7. II 7 raises a new issue, i.e. the apparent impossibility of disentangling a procedure which establishes the essence of something and a procedure which establishes the existence of the same thing. If the situations described in II 3 and in II 7 are the only options on the table, the picture sketched in II 
1-2 is seriously challenged and, in this sense, II 3-7 do build a genuinely aporetic discussion.

The paper is divided into three parts. In the first part I analyse the ways in which Aristotle opens, closes and refers back to the discussion in II 3-7 and derive from this analysis some general ideas about the general scope of the discussion in these chapters. In the second part, I provide an overview of II 3-7 emphasizing the points which I take to be relevant for answering the two general questions I introduced above and provide an answer to the second question, i.e. whether and in what sense II 3-7 can be regarded as an aporetic discussion in the economy of $A P_{0}$ II. In the third part, I spell out some overarching features of the discussion in II 3-7 which may help us get a better grasp on the problems Aristotle considers in these chapters and therefore provide an answer to the first question.

\section{THE SCOPE, STRUCTURE AND OUTCOMES OF THE DIFFICULTIES IN II 3-7}

The opening lines of II 3 and the closing lines of II 7 , respectively, introduce and conclude the section I intend to deal with. These lines are important because they give us some clues as to the scope which Aristotle ascribes to the discussion in II 3-7. Let us start with the opening lines of II 3:

90a36-38: "Let's say (a) how the what-it-is (

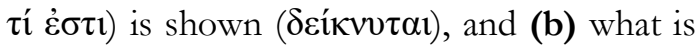
the way of the reduction ( $\tau$ ís ó $\tau \rho o ́ \pi \mathrm{s} \varsigma \tilde{\eta} \varsigma$ $\dot{\alpha} v \alpha \gamma \omega \gamma \tilde{\eta} \varsigma)$, and (c1) what is a definition 
(ópı $\mu$ ós) and (c2) of what things it is, first unfolding difficulties about these things" 5 .

(a)-(c2) are not yet the difficulties Aristotle is going to discuss in II 3-7. Rather, they set the general topic of the whole discussion in II 3-10 (and perhaps later chapters), with respect to which II 3-7 unfold some difficulties. One outstanding feature of (a)-(c2) is that they all relate to definition: (a) concerns the way in which the traditional object of a definition (the what-it-is) is "shown"; (b) is about the "reduction" or "leading back" (presumably: of such a procedure) to something else; (c1) and (c2) explicitly ask what a definition is and what its object is. While the exact meaning of these questions is not yet clear, it is clear that they are all about definition.

The results of the discussion in II 3-7 are summed up at the end of II 7:

92b35-38: "From these things, then, it appears that (i) neither are definition (óplouós) and

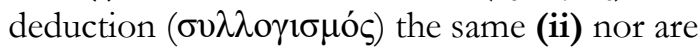
deduction and definition of the same thing; in addition, it appears that (iii) neither does the definition demonstrate or show (ov̌ $\tau \varepsilon$

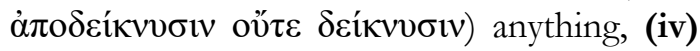
nor is it possible to know ( $\gamma v \tilde{\omega} v \alpha l)$ the what-itis ( $\imath$ ò $\tau$ í $\dot{\varepsilon} \sigma \tau \imath v$ ) by definition or by

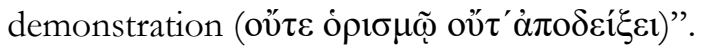

5 Unless otherwise indicated, translations are mine. The introduction of letters (a)-(c2) is mine too and I shall use it constantly to refer to the corresponding portions of the text throughout the paper. 
While (a)-(c2) in II 3 are the rubrics of topics for investigation, (i)-(iv) are the conclusions of the discussion in II 3-7 and, if all true, are supposed be problematic (whether all of them or only some of them are meant to be problematic is an issue we shall return to). These conclusions focus on the relation between definition, deduction and demonstration, but at least some of them are formulated as points about definition and the what-it-is as such: (iii) claims that the definition does not demonstrate and does not "show" anything; (iv) claims that the what-it-is cannot be known by definition or by demonstration. If one focuses on the conclusions of the discussion in II 7, however, it is easy to miss the shift in emphasis from II 3 to II 7: the issues introduced in II 3 revolve around the what-it-is and definition quite generally; the summary in II 7 emphasizes some problematic aspects concerning the relation between definition and deduction, even if some details in II 7 still suggest that the broader focus on definition - not only with respect to deduction, but, more generally, as something which is meant, somehow, to give us access to the what-it-is - is still relevant.

While the shift in emphasis from II 3 to II 7 certainly reflects Aristotle's main interests in these chapters, I think the broader scope of the discussion as it is spelled out at the beginning of II 3 is important to appreciate the difficulties Aristotle intends to tackle. There is a general question which is: how is the what-it-is "shown"? I take it that traditionally the procedure through which this is done is regarded as a procedure of "defining", which culminates in the formulation of a proposition in which the predicate expresses the what-it-is of the subject. The problems that II 3-7 bring to the fore concern the nature of this procedure and its relation to other procedures, such as deducing and demonstrating, which are also meant to yield some progress in knowledge. Demonstrating in Aristotle's technical sense, i.e. formulating a deduction in which the premises are prior 
to the conclusion in the sense that they express the cause of the conclusion, is one such procedure. But it is certainly not the only one: carrying out an induction, dividing concepts, etc. are other procedures which may also play a role in defining. Note, furthermore, that, next to Aristotle's technical and strong understanding of demonstrating as displaying a causal structure, a looser understanding of demonstrating (as formulating a deduction in which the premises enjoy some priority with respect to the conclusion and yet do not provide a causal explanation of the conclusion) also belongs to Aristotle's conceptual framework.

I believe both textual evidence and further considerations about the development of the argument in II 3-7 suggest that the broader scope introduced in II 3 keeps being relevant throughout the whole discussion. One detail I would like to focus upon is the occurrence of the verb $\delta$ cíkvv $\mu$ both in (a) in the opening lines of II 3 and in the opening lines

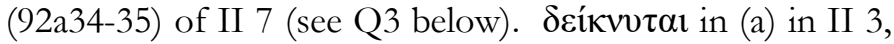
$90 a 36$ is usually taken in the sense of "is proved" or "is demonstrated". I shall address below the reasons which may

${ }^{6}$ Cf. the translations: Barnes 1993, p. 49: "Let us now say how we can prove what something is"; Detel 1993, Bd. I, 61: “ [...] wie aber das Was-es-ist bewiesen wird"; Mignucci 2007, p.97 "Diciamo ora come si prova il che cos'è". See also the references in n. 2. In his commentary (Bd. II, p. 570) Detel adds: "Die Übersetzung von $\delta \varepsilon 1 \kappa v v ́ v \alpha l$ durch "beweisen" in (i) ist vielleicht ein wenig scharf; die Parallelstelle II 7, 92a34-b3 legt die Annahme nahe, daß Aristoteles zu Beginn von II3 die genauere Weise der Etablierung von Definitionen möglicherweise noch offen lassen will; andererseits ist dann in II3 und II4 doch hauptsächlich vom "Beweisen" (vgl. Z. B. 90b5-7, 91a12-15) oder sogar vom Demonstrieren (vgl. z. B. 90b3, 13, 18-19, 22-27, 31, 33; 91a1-2, 611, 13, b10) des Was-es-ist die Rede; das Beweisen dürfte also die wichtigste Nuance von $\delta \varepsilon 1 \kappa v v ́ v \alpha 1$ darstellen (wie Aristoteles auch selbst in II 7, 92b35-38 klarstellt)". Similarly Angioni 2004, p. 21: 
have led interpreters to favour the overall interpretation of these chapters which is behind this rendition. Further reasons may hang together with the way in which (b) and the "reduction" (anagoge) there mentioned are understood". However, and independently of what one thinks of anagoge, (a) and (b) are two distinct questions and, even if part of what Aristotle is going to discuss is whether the what-it-is can be shown through a deduction or a demonstration, this does not seem to require that we restrict the sense of $\delta \varepsilon i ́ \kappa v v \tau \alpha$ to what is achieved through a deduction or a demonstration. More generally, I think Aristotle clearly hints at the fact that the family of problems he is concerned with in these chapters is not exhausted by the relation between defining and deducing (let alone demonstrating). In fact, the beginning of II 7 emphasizes the general problem of how the definer "will show (92a34: $\delta \varepsilon i \xi \varepsilon 1)$ the essence or the what-it-is", if she does not show it "as the one who demonstrates ( $\dot{\omega} \zeta$ $\left.\dot{\alpha} \pi 0 \delta \varepsilon \iota \kappa v \varsigma_{\varsigma}\right)[\ldots]$ nor as the one who carries out an induction

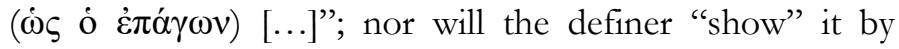

“...de que maneira pode-se provar o o que é...”. Angioni 2004, p. 99, however, clearly distinguishes the technical usage of deiknusthai (which he translates with "provar") from the looser usage ("mostrar"). Angioni is completely right in pointing out that both usages are present in Aristotle (he also provides a list of occurrences for each). I claim that the looser usage rather than the technical one is at play in II 3 and in the passages I shall refer to in the course of the paper.

7 In APr I 32-46 and II 23-27 Aristotle resorts to the same expression to indicate the resolution of various forms of arguments into syllogistic figures and moods and one might think that this is what Aristotle has in mind here too (in fact, at $90 \mathrm{~b} 1 \mathrm{ff}$. and in $A P o$ II 4 he addresses the issue of the kind of syllogism which would have a proposition of the form of a definition, i.e. a universal affirmative proposition, as its conclusion). I spell out the difficulties involved in this account in section 4. 
resorting to perception or by pointing at it with the finger. Furthermore, the concluding lines of II 7 suggest that we are left with the puzzling result that "it is not possible to know $(\gamma \nu \tilde{\omega} \vee \alpha l)$ the what-it-is by definition nor by demonstration". Within this context, translating the occurrence of the same verb $\delta \varepsilon i ́ \kappa v v \mu$ that we have at the beginning of II 3 with "prove" or "demonstrate" would clearly be inappropriate 8 , given that Aristotle indicates a list of procedures the definer could engage in and that demonstrating (i.e. resorting to a deduction of a specific kind) is only one of them. Furthermore, II 8, 93b15-20 reaches the conclusion that, although there is no deduction or demonstration of the what-it-is, the what-it-is of things whose cause is different

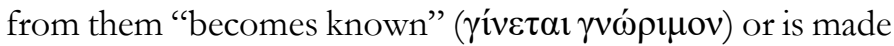
clear (II 8, 93b17: $\delta \tilde{\eta} \lambda$ ov; II 9, 93b27: $\delta \eta \lambda \tilde{\omega} \sigma \alpha \mathrm{l}$ ) through deduction and demonstration. As for things whose cause is not different from them, what they are and their what-it-is "must be set by hypothesis or made manifest in another way"

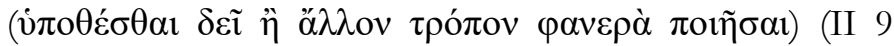
93b21-24) .

On the basis of these considerations, I think that (a) in II 3 introduces a more general issue than it is usually assumed.

\footnotetext{
${ }^{8}$ Note that both Ross and Barnes, who take $\delta \varepsilon i ́ \kappa v v \tau \alpha l$ in the sense

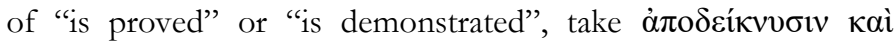

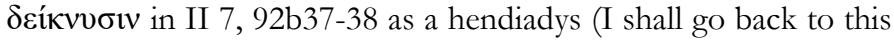
point below). Detel 1993, Bd. I, 67 keeps the distinction and translates "demonstriert oder beweist" (on the use of "beweisen" as a translation for $\delta \varepsilon i ́ \kappa v v \mu 1$ see fn. 6). Similarly Angioni 2004, p. 37, "demonstra ou prova" (on which see also fn. 6).

${ }^{9}$ The issue of how these immediate principles are apprehended is notoriously and problematically taken over again in II 19. I believe, however, that reference to II 8-9 is in order here since the agenda set at the beginning of II 3 rules (at least) the whole discussion in II 3-10, as section (d) in the text above and the summary in II 10, 94a14-19 clearly suggest.
} 
The issue is the problem of how the what-it-is can be made known ${ }^{10}$. Whether deduction and, more specifically, demonstration can or cannot play any role in tackling this problem is a fundamental question, but the basic issue Aristotle starts to raise in II 3 is more general. Similar considerations apply to the final lines of II 7 (quoted above),

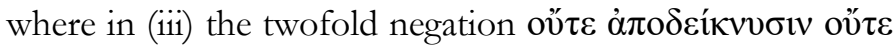
$\delta \varepsilon i ́ \kappa v v \sigma ı v$ should be taken seriously: a definition "neither demonstrate nor shows" anything.

In addition to the textual evidence, it seems to me that the general reading of (a) I propose has the advantage that it keeps making sense once we are aware of some of the difficulties emerging in the course of II 3-7. In particular, one of the difficulties will be that it is sometimes hard to draw a neat distinction between the proper object of a definition or a demonstration (i.e. what a definition or a demonstration is of) and other things which become evident through a process of defining or demonstrating. Accordingly, it might turn out that the what-it-is is "shown" in the course of a process (say: in the course of a demonstration) without being the proper object of that process (e.g. without being what the demonstration is of strictly speaking). The broader understanding of (a) makes room for this possibility - which, I think, is an advantage given that such a possibility cannot be excluded upfront.

\footnotetext{
${ }^{10} \mathrm{It}$ is worth noting that the more general issue of how the whatit-is can be shown and of whether it can be made known at all is something Aristotle clearly has on his mind. See, for instance, Met. VI 1, 1025b11-16, where Aristotle distinguishes the ways in which

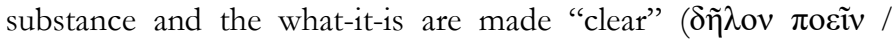
$\tau \rho o ́ \pi \circ \varsigma \tau \tilde{\eta} \varsigma \delta \eta \lambda \omega ́ \sigma \varepsilon \omega \varsigma)$ from the way in which per se attributes are enquired into (1025b12-13: by more or less cogent demonstrations); Met. VIII 3, 1043b23-32, where Aristotle discusses the difficulty of Antisthenes' followers, who doubt whether the what-it-is can be defined at all.
} 
Before turning to the development of II 3-7, however, I would like to address a possible worry about my approach and to clarify a few points of my proposal. For there are elements in these chapters which may encourage the reader to take the relation between definition and demonstration as the issue of the discussion. To start with, with reference to the general framework sketched in II 1-2 and the idea that definition and demonstration converge onto the enquiry into a middle term, questioning the relation between definition and demonstration is a fairly natural move. Furthermore, in the opening lines of II 8 (93a1-3) Aristotle manifests the intention to re-analyse what the former chapters seem to have established and, in doing this, he gives the following summary:

93a1-3 "Starting again, we have to inspect what of these things has been said well and what has not been said well, and what the definition is and whether in some sense there is

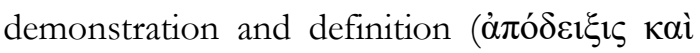
ópı $\mu$ ós) of the what-it-is or there is no sense at all in which this is the case."

This text can suggest that the discussion of II 3-7 was primarily meant to challenge the idea that there is some sense in which "there is demonstration and definition of the whatit-is" and one might think that this formulation should discourage the broader interpretation of II 3-7 I intend to sketch. I do not think this is the case: my reading is not in conflict with the claim that the relation between definition and demonstration is one of the crucial points (possibly: the crucial point) in Aristotle's discussion. In fact, in II 3-7 Aristotle approaches (a)-(c2) by breaking down the discussion into three fundamental questions, one of which is indeed whether it is possible to know the same things (and, in particular, the what-it-is, which is traditionally regarded as 
what the definition discloses) in the same respect by definition and by demonstration. The three questions, which give the structure of the discussion in II 3-7, are the following:

Q1 Is it possible to know the same thing in the same respect by definition (ópı $\sigma \mu \delta)$ and by demonstration (’่ $\pi$ ó $\delta \varepsilon 1 \xi 1 \zeta)$ ? (II 3, 90b2-3, dealt with in II 3);

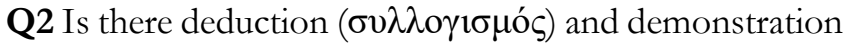

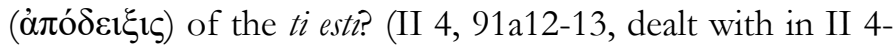
6) ${ }^{11}$;

Q3 How will the definer show ( $\delta \varepsilon \dot{\xi} \xi \varepsilon \mathbf{l})$ the substance or the what-it-is? (II 7, 92a34-35, dealt with in II 7).

While all of Q1-Q3 as a whole fall under the enquiry about definition and the what-it-is introduced at the very beginning of II 3, each of Q1-Q3 is more specific. One can, of course, think that an answer to Q1 will imply an answer to Q2 and Q3 and that, conversely, an answer to Q2 will be or imply an answer to Q1 and Q3. In this sense, certainly figuring out the relation between definition and demonstration will have implications for the account of what it is that a definer does when she defines the what-it-is of something. Although I believe this picture would in any case require some qualification, I do not intend to deny the obvious, namely that there is some fundamental sense in which the relation between definition and demonstration is the core issue of these chapters. What I claim is that there must be a sense in which Q3 keeps being an intelligible question once it is ruled out that the definer demonstrates anything. Furthermore, the way in which Q2 is spelled out in II 4-6 turns out to be rather specific: the question there turns out to be whether one can produce a demonstration having a definition as its conclusion. However, the whole discussion

${ }^{11} \mathrm{I}$ take the opening lines in B 6 as introducing issues that are subordinated to Q2. On the structure of B 4-6 and on the relation between B 4-6 and B 3 see section 3 below. 
of II 3-7 strongly suggest that this is not the only way in which the relation of defining to deducing and demonstrating can be understood - or so I shall argue. In fact, more general concerns about what a definition is keep coming up, as the very beginning of II 8 confirms: "Starting again, we have to inspect what of these things has been said well and what has not been said well, and what the definition is $[\ldots] "$.

\section{AN OVERVIEW OF THE ARGUMENT IN $A$ Po II 3-7}

After the announcement of the topic of the discussion at 90a36-38, at 90b2-3 Q1 (whether it is possible to know the same thing in the same respect by definition and by demonstration) sets up the discussion in II 3. The chapter displays a rather neat tripartite structure, corresponding to the three conclusions established in it. The conclusions are stated at 91a7-11: not everything that has a definition has a demonstration (established at 90b19-27); not everything that has a demonstration has a definition (established at 90b5-17); it is never the case that the same thing has both a demonstration and a definition (established at 90b28-91a6).

Even without going into details, both Q1 and the phrasing of the conclusions make it clear that the analysis of the relation between definition and demonstration is objectoriented: the relation obtaining between definition and demonstration mirrors (or perhaps is dependent upon) the relation between their respective objects or domains. This may sound as a relatively unproblematic point, but it actually rests on a series of assumptions which it might be helpful to make fully explicit. A definition is said to be of the what it is or of substance (a definition is of the ti esti or makes clear $(\delta \eta \lambda$ oĩ) the ti esti at 90b1-2, 90b30, 91a1; a definition is of substance or makes some substance known at 90b16, 90b3031). Whatever a what-it-is or a substance (or the substance 
of something) turns out to be, these seem to be items that are picked out by terms or term-like expressions. The way in which the objects of demonstration are characterised is in a way more complicated. At 90b13-16 Aristotle suggests the following. The claim that there is no definition of all things of which there is demonstration gains adequate credibility (ikane pistis) by induction: for, we do not come to know any of the attributes per se and of the accidents ${ }^{12}$ by giving a definition of them ${ }^{13}$. In the immediately following lines (90b16-17) the argument is added that, while definition is of substance, none of these (i.e. per se attributes and accidents) are substances ${ }^{14}$. This suggests a sort of discrete partition of non-propositional items into what-it-is / substances, which can be defined, and attributes per se / accidents, which cannot be defined. However, Aristotle oscillates between saying that what is deduced or demonstrated is the conclusion, i.e. the proposition stating that a predicate belongs or does not belong to a certain subject ${ }^{15}$, and saying that what is made clear or

12 I don't think that the addition of accidents (symbebetkota) here implies that they can be the objects of demonstration, contrary to Aristotle general tenet that there is no demonstration of accidents, but only of per se attributes. I think the argument is simply mentioning cases of items we do not seem to know by definition, but in other ways - of these, a subgroup is that of items of which we gain knowledge by demonstration.

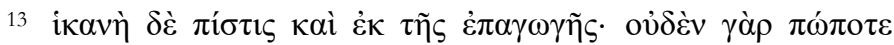

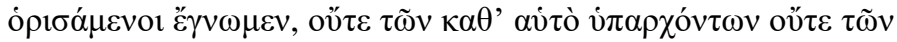
$\sigma v \mu \beta \varepsilon \beta \eta \kappa o ́ \tau \omega v$.

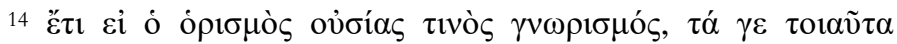

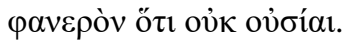

15 There are passages suggesting that the object of demonstration is a proposition or a state of affairs (e.g. a demonstration shows the boti cf. II 3, 91a1-2) - they can all be rephrased in terms of: the 
plain by a demonstration is the property, i.e. what is indicated by the predicate of the conclusion ${ }^{16}$. For example, in APo I 7,75a39-b2, we find in one and the same period the idea that

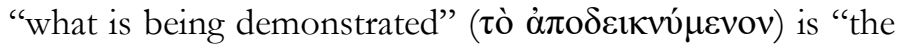
conclusion (this is what belongs to some kind in its own

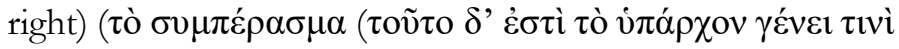
$\kappa \alpha \theta$ ' $\alpha$ i $\tau$ ) $)$ )" and the idea that a demonstration "makes plain $(\delta \eta \lambda \circ \tilde{\mathbf{l}}) \ldots$ the affections and the attributes per se ( $\tau \dot{\alpha} \pi \alpha \dot{\theta} \theta \eta$

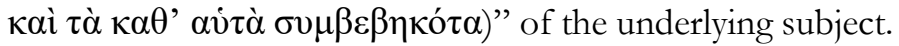
This oscillation suggests that, even when Aristotle speaks of the object of a demonstration in terms of attributes or accidents (as he does in II 3), what he actually means is that a demonstration "shows" or "makes plain" that and/or why some determinate attribute belongs to some determinate subject. The same idea can be found in Aristotle's claim that all demonstrations show something of (or: with reference to) something (ti kata tinos deiknusin) (90b33-34).

These claims raise a number of questions which I cannot tackle here ${ }^{17}$, but the only point I intend to emphasize is how this way of thinking of objects of demonstration and of objects of definition allows us to see how Aristotle comes to discuss the issue of whether the what-it-is can or cannot be known by deduction or demonstration in II 4-6 (see Q2 above). Aristotle can start with the claim that a definition is of the what-it-is, i.e. the what-it-is is what we know by definition. The what-it-is is always the what-it-is of a subject.

demonstration is of a certain property, i.e. it shows of it what subject it belongs to and why.

16 Only proper predication (and not the sort of accidental predication described in $A P_{0} \mathrm{I} 22$ ) is relevant here.

17 A detailed discussion of whether this characterization can be applied to composite substances and to their forms and of further issues concerning essence and per se predication can be found in Peramatzis 2010. 
The question whether it is possible to know the same thing in the same respect by definition and by demonstration can now get a more precise formulation. The question whether we can have a demonstration of what is known by definition becomes the question of whether we can demonstrate the what-it-is, i.e. whether we can produce a certain deductive argument showing that and/or why a certain what-it-is belongs to a certain subject.

This train of thought leads directly to II 4, where Aristotle relies on his account of definition as a kind of predicate in Top. I 8, 103b9-10, i.e. as a predicate that converts with the subject (i.e. it is predicated of all and only the same things of which the subject is predicated) and expresses the essence of the subject (where both subject and predicate are universal term-like expressions). Accordingly, we will be looking for a middle term of a deduction whose conclusion is a universal affirmative proposition, in which the predicate $\mathrm{A}$ is convertible with the subject $\mathrm{C}$ and expresses the essence of C. Aristotle argues that the only way to build such a syllogism is through a middle term $\mathrm{B}$ which is in its turn convertible with both $A$ and $C$ and such that $B$ expresses the essence of $\mathrm{C}$ and $\mathrm{A}$ expresses the essence of $\mathrm{B}$. But, if this is the case, i.e. if $B$ is convertible with $C$ and expresses what $C$ is, then $B$ will already express the what-it-is of $\mathrm{C}$. In other words, in order to prove that $\mathrm{A}$ is the what-it-is of $\mathrm{C}$, we have to assume that $\mathrm{B}$ is the what-it-is of $\mathrm{C}$. If we do not assume such a $\mathrm{B}$, we cannot produce a deduction with the desired conclusion. In particular, if $\mathrm{B}$ does not express the what-it-is of $\mathrm{C}$ and $\mathrm{A}$ does not express the what-it-is of $\mathrm{B}$, we might get a conclusion that is true, but $A$ will not express the whatit-is of $\mathrm{C}$. On the other hand, if we do assume such a B, what we get is not a demonstration (a deduction such that the conclusion follows from premises which are prior and better known), because what has to be shown has already been assumed (91b7-11). 
The move from II 3 to II 5 and 6 is less straightforward. In II 5 Aristotle discusses the way in which definitions are obtained through division, which in $A \operatorname{Pr} \mathrm{I} 31$, 46a35-37 is explicitly referred to as a method people use in the conviction that it is possible to produce a demonstration (apodeixin) of substance and of the what-it-is. More specifically, Aristotle discusses how division and deductive steps are intertwined in the relatively complex procedure which is by some people regarded as a method to demonstrate (i.e. to deduce from what is prior) the what-itis of a certain subject ${ }^{18}$. II 6 focusses on two types of deductive argument ex hypotheseōs (respectively: II 6, 92a6-19 and II 6, 92a20-33), both explicitly codified by Aristotle himself in the Topics (respectively: Top. VII 3, 153a14-15 and 153a26-31; cf. also VI 9, 147a31-b1) as ways to formulate a sullogismos of a definition or to establish (kataskenazein) a definition. The first kind of argument considered in II 6 (92a6-19) is that in which one assumes the account of the essence as a general premise (1): 'the essence of something is the convertible property consisting of the features constituting the what-it-is of it' (cf. Top. VII 5, 154a25-29). The second premise of the argument would be about a specific subject $S$ for which we already have such a set of features $\mathrm{P}$. The second premise would then be something like (2): 'P is convertible with $\mathrm{S}$ and consists of all and only the features constituting the what-it-is of S'. From this the conclusion would follow: ' $\mathrm{P}$ is the essence of $\mathrm{S}$ '. The second case (92a19 ff.) is that in which one establishes that a predicate $\mathrm{P}$ expresses the what-it-is of a subject $\mathrm{S}$ by

${ }^{18} \mathrm{I}$ think it is important to stress that in $A P r$ I 31 Aristotle does not simply deal with division, but with complex argumentative procedures which, possibly next to genuinely deductive steps, include the use of the procedure of division. I have spelled out this point in greater detail also with reference to Alexander's views on it in Castelli 2015. 
assuming that the contrary of $\mathrm{P}$ expresses the what-it-is of the contrary of $S$ in conjunction with the general claim that, if both the subject and the predicate have contraries and the contrary of the predicate indicates the essence of the contrary of the subject, then the essence of the subject is expressed by the predicate. Aristotle claims that in this case, too, the essence is assumed (92a24), even if it is not the essence which has to be proved to be the essence of the subject.

Many details fall out of this outline, but it should be clear that in II 6 as well as in II 4 and 5, Aristotle considers cases in which it might be difficult to separate sharply a deductive moment from a definitional moment. There is an issue as to what "establishing" something (as opposed to "deducing" something) exactly amounts to ${ }^{19}$, but it seems clear that one can use a claim $\mathrm{P}$ (a proposition) actually deduced from certain premises in order to establish, i.e. in support of, a submitted proposition $\mathrm{Q}$ which is distinct from P. What Aristotle thinks about the logical link between P and Q, whether what he thinks on this issue rests on some primitive theory of logical consequence, is a very difficult and controversial issue. What is clear is that the cases discussed in II 6 certainly display a deductive structure in an argument used in support of a given definition.

For each of the four types of arguments in II 4-6 Aristotle raises specific pieces of criticism, but there are two overarching issues with these types of arguments which explain why the conclusion of II 3 is eventually not seriously challenged in II 4-6. Firstly, while each of the four types of arguments discussed in II 4-6 is, in part or as a whole, deductive, they are all question begging (II 4, 91a31-32; cf. 91b9-11; II 5, 91b15-20; II 6, 92a9-10, a24) in that either some of the premises directly assumes that the what-it-is of

${ }^{19}$ I deal extensively with this issue in Castelli, "Aristotle on topical arguments", in preparation. 
the subject under investigation belongs to it or some of the premises assume the what-it-is of a subject which is distinct from the subject of the conclusion (e.g. its contrary) but is not prior to it (rather, the premise and the conclusion have exactly the same epistemic status and a move from the premise to the conclusion cannot therefore track any progress in knowledge ${ }^{20}$. Accordingly, even those cases in

${ }^{20}$ The syllogisms in first figure discussed in II 4 are in some sense analogous to those used in support of the claim that everything (including principles and, among those, definitions) can be demonstrated by resorting to circular proof ( $A P o$ I 3 ), although circular proofs involve their own complications. It is in any case important to stress that the failure to comply with the requirements of priority typical of demonstration cannot be simply captured in terms of mutual implication; for an excellent discussion of this point see Angioni 2018. The reason why in arguments by division, too, the what-it-is is assumed and not demonstrated is that at each step of the division one has to assume under which side of the division the subject falls without further explanation. More precisely, Aristotle admits that the supporters of division could / would say that the subject under investigation falls under one side of the division because it does not fall under the other. But this answer does not provide any positive and substantive ground for the positive ascription of a certain property to the subject. In this sense, each step in the process of division is like the conclusion of a syllogism in which the middle term is not displayed: it is always possible to ask why it is the case that the predicate belongs to the subject (II 5, 91b20-21; 91b35-92a1). Finally, in the first kind of argument considered in II 6 (92a6-19) the problem is that (2) simply states that $\mathrm{P}$ complies with the requirements for expressing the what-it-is of $\mathrm{S}$, but this is what should be shown through a middle term (92a10). In the second type of argument (92a19 ff.) the problem is that contraries are interdefinable. This implies that a definition based on the definition of a contrary is not based on premises that are prior and better known than the conclusion, and this is one of the ways in which a form of indirect petitio principii is 
which it may look like defining and deducing overlap are not cases in which defining and demonstrating overlap, since the relation between premises and conclusion fails to meet some basic requirements for demonstrations. Secondly, none of the arguments discussed in II 4-6 can establish some features of the predicate of the conclusion, i.e. of the what-it-is, namely its unity and the fact that it belongs essentially (rather than in any other way or without qualification) to its subject $^{21}$. I take it that the latter issue introduces an important aspect of the whole discussion in these chapters to which I shall return in section 4: there is a difficulty in telling what and "how many" things are shown through definition or demonstration and there is one further difficulty in telling whether all or only some of them are what a definition or a demonstration is of strictly speaking, while the rest is still somehow "shown" or "made manifest" through the same process but somehow indirectly. This point is important because Aristotle seems interested in preserving a sort of meta-principle according to which some formal features of definition and of demonstration and, more generally, of epistemic processes and states, depend upon some corresponding features of their objects. For example, in II 3 the relation between definition and

carried out (Top. VIII 13, 162b35, 163a11-12; cf. $A \operatorname{Pr}$ II 16, 64b3965a9).

${ }^{21}$ The issue of unity is explicitly emphasized only for the arguments considered in II 5 and 6: neither division nor the two types of arguments based on a hypothesis show why (dia ti) each of the predicates building the definition belongs to the subject as a unity (II 6, 92a27-33; cf. II 5, 91b20-21, 91b35-92a1). It is less obvious that this piece of criticism applies to the arguments discussed in II 4 (for a different opinion see Charles 2000, pp. 179-196). I take it that none of the arguments in II 4-6 can show that the predicate belongs to the subject essentially (i.e. as the what-it-is is supposed to belong to its subject) without begging the question. 
demonstration is dependent upon the relation between their domains (see e.g. II 3, 91a9-11); or again, the unity of a science depends on the unity of its object (II 3, 90b20-21; cf. I 28, 87a38-39) and, similarly, definition and demonstration are, each, of one thing (II 7, 92b9-11). If it turns out that one cannot identify what a definition or a demonstration are of exactly, one might think that the very basic conception of definition and of demonstration involved in the discussion is untenable.

In short, the moral to be drawn from II 4-6 seems to be this: all argumentative procedures discussed in II 4-6 are partially or wholly deductive procedures which can be (and, at least in some cases are in fact) used in order to obtain (II 5) or to establish (II 6 and possibly II 4) a definition. II 4 explicitly deals with a sullogismos in Aristotle's technical sense of the Analytics (91a14-15: "For, the syllogism shows something of something else through the middle"). II 5 deals with a procedure to obtain definitions by adding up the results of several divisions; there can be deductive moments involved in this procedure, but what can be deduced is not the desired definition (still, as Aristotle points out in $A P r$ I 31, one can say that one has to do with a asthenés sullogismos, a "weak deduction"). II 6 deals with arguments which in the Topics are meant to fall under the general account of sullogismos of Top. I $1^{22}$ and, more specifically, are regarded as sullogismoi ex bypotheseōs following the account of the Analytics. The use of deductive procedures in the context of the enquiry aiming at a definition might cast doubts on the sharp cut between definition and demonstration established in II 3, but the discussion in II 4-6 points out that the intertwining of deduction and definition does not challenge the

${ }^{22}$ A thorough discussion of the notion of sullogismos in the Rhetoric, the Topics and Sophistical Refutations can be found in Castelli and Rapp, (in progress). 
separation of definition and demonstration since none of the deductions in II 4-6 is a demonstration.

Having dismissed in II 4-6 possible difficulties for the conclusion reached in II 3 that demonstration and definition are distinct since there is no overlap between that of which definition and demonstration respectively are, in II 7 Aristotle turns to the more radical question of how the definer can make the substance or the what-it-is known. Aristotle addresses this question twice (at 92a34-35 and at 92b4). I take it that the first time he focuses on what the definer "does" when she gives a definition, how she shows the what-it-is, whereas the second time he focuses on what it is exactly that the definer shows - not how she shows the what-it-is, but how can she show the what-it-is (and the whatit-is only). In other words, Aristotle addresses both the nature of the procedure of defining and the object to which we gain access through such a procedure. In this respect, II 7 addresses both aspects (objects and nature of a procedure which is supposed to mark a progress in knowledge) introduced in the course of II 3 and II 4-6.

I take II 7 to presuppose the whole discussion in II 3-6. II 3 argues that definition and demonstration deal with separate sets of objects and II 4-6 show that what could be given as instances of an overlap are not cases of demonstrations. So, the definer does not demonstrate the what-it-is. Nor can she resort to induction to show what something is: induction at most shows that something is the case by showing that none of the cases considered gives evidence to the contrary. For instance, induction can show that human beings are terrestrial animals, that they normally have two legs and so on, but it cannot show what it is to be a human being. Nor will perception or a deictic gesture do (by seeing a human being or by pointing at one we do not come to know what it is to be a human being).

The rest of the chapter takes us one step further and questions the very possibility that the definer may show or 
get us to know anything at all (independently from the methods she follows). The section starting at $92 \mathrm{~b} 4$ is the first part of a dilemma, whose second part is presented in 92b2634 . Here is a very sketchy reconstruction of the argument unfolding at 92b4-34:

(1) Either (a) the definer shows the what-it-is or (b) she shows what the name signifies.

(a)

(2) If she shows the what-it-is <of something>, she will have to show at the same time that something is ${ }^{23}$.

(3) But she cannot show with the same logos (be it definition or demonstration) the ti esti and the hoti esti.

(4) Therefore, the definer cannot show the ti esti.

23 Why this should be the case is far from obvious. For some discussion on this point see for example Bolton 1976, Devereux \& Demoss 1988, Charles 2000, pp. 57-76, Bronstein 2016, pp. 144 ff. The first three discussions focus on the relation between definition and existence emerging from the difficulties in II 7 and explore the consequences that this relation has for characterizing Aristotle's essentialism. A rather different reading of the whole discussion in II 3-8 is given by Bronstein 2016, who rather takes the main puzzle of the discussion to concern the possibility of inquiring into and establishing whether something exists (rather than what something is, as other interpreters claim). If I am right about some details of the difficulties, the two readings (the traditional one, claiming that the difficulty concerns the possibility of enquiring into the essence of something, and Bronstein's interpretation, rather focusing on the possibility of enquiring into the existence of something) are not mutually exclusive, but rather emphasize two complementary aspects of one and the same puzzle. I agree with the traditional interpretation in that I think the focus of the discussion in II 3-7 is on definition and essence; but I think Bronstein is right in pointing out the (in my view: complementary) difficulty concerning existence. 
(b)

(5) If she shows what the name signifies, there will be definitions of non-substances and non-beings in general (and all the other consequences listed at 92b28-34).

(6) But all this (92b28-34) is absurd.

(7) Therefore, the definer does not show what the name signifies.

The implicit conclusion of the whole argument is:

(8) Neither does the definer show the ti esti nor does she show what the name signifies, i.e. the definer does not show anything.

Each step in this argument raises a number of issues which I cannot discuss here ${ }^{24}$. (8) provides the missing part of (iii) in the concluding lines of II 7 by pointing at the difficulty that, no matter what the definer does (and it does not look like she can do much), she cannot get to the what-it-is. But if the what-it-is cannot be shown by the work of the definer (i.e. by defining, whatever that process turns out to be) nor, as has been shown, can it be shown by deduction (and, a fortiori, by demonstration), it looks like the task of knowing the what-it-is is hopeless.

To conclude this overview of II 3-7, I would like to return to the second question I raised at the beginning of this paper, namely whether and in what sense II 3-7 can be regarded as an aporetic section functional to the argument in APo II. I take it that Aristotle's argument in these chapters is

24 One such issue is whether "to show" in (1) (a) and in (1) (b) means the same. Some discussion on this issue can be found in the literature referred to in fn. 23. In any case it seems to me that the more general understanding of "showing" which I propose in section 2 would make sense in both (a) and (b). 
something along these lines: there is some sense in which enquiring into what something is and enquiring into why something is the case amount to the same thing, despite being distinct types of enquiry; showing what something is amounts to defining it, showing why something is the case amounts to demonstrating is. Accordingly, defining and demonstrating must be distinct procedures which, at least in some cases, converge on or share an enquiry into a middle term. II 3 argues that defining and demonstrating are not only distinct but non-overlapping; the distinction is basically established based on the relation obtaining between their respective objects or domains (i.e. the domain of what is definable and the domain of what is demonstrable). II 4-6 discuss four cases of entanglement between defining and deducing within procedures linked to the formulation or to the establishment of a definition. While these cases may seem to question the clear-cut distinction between defining and demonstrating, it turns out that they do not challenge the result of II 3. II 7, however, presents a different and more serious challenge: it does not seem possible to show what something is without at the same time showing that the thing exists. But, if this is so, it seems difficult to isolate defining as a distinct procedure to get knowledge of one definite type of object as well as to isolate demonstrating as a distinct procedure which can establish the existence of something. It turns out that, if the complete separation in II 3 and the impossibility of a neat distinction between the objects of definition and the objects of demonstration in II 7 are the only options, the broader picture of the relation between the different types of enquiry in II 1-2 is in danger.

Of the whole set of chapters 3-7, II 3 is the only one explicitly described as unfolding aporiai: apart from diaporèsantes at 90a37-38 - which could be taken to refer to the whole of II 3-7-aporèseie at 90b1, diēporèsthō at 91a12, en tois diaporemasin at 93b20 all refer to the discussion in II 3. This is quite remarkable, especially given the fact that 
Aristotle seems to believe that the results achieved in this chapter are fundamentally correct (II 8, 93b16-17, b19-20). Within the scope of II 3-7, however, II 3's conclusions (i.e. (i) and (ii) in the closing lines of II 7) do constitute a problem: they represent a crucial threat to the tenet advanced in II 2 and made plain only by the end of II 10 that both the enquiry into what something is (and, therefore, the practice of defining something) and the enquiry into why something is the case (and, therefore, the practice of demonstrating something) are enquiries into a middle term. On the one hand, the straightforward identification of definition and demonstration does not seem to be a viable option; on the other hand, if one cannot clearly disentangle what it is that definition and demonstration are of, the very possibility of preserving a neat and useful distinction between definition and demonstration might be in jeopardy. And, if so, the very basic tenets of II 2 might have to be dismissed. I take it that this is why the whole final section of II 7 marks the conclusion of a properly aporetic discussion ${ }^{25}$.

\section{SOME OVERARCHING FEATURES OF THE DISCUSSION IN II 3-7}

Based on this sketchy overview, I would like to draw attention to some overarching features of the discussion in II 3-7 which may help understand some of Aristotle's

25 Two further points can be established on the basis of the foregoing analysis. First, there are no special difficulties in taking tōn echomenon logon at $90 \mathrm{~b} 1$ as a reference to what follows (instead of as a reference to what precedes). II 3 is really the beginning of an aporetic discussion which ends in II 7 and prepares the analysis in II 8-10. Second, II 4-6 are not aporetic chapters strictly speaking: they all establish results Aristotle is committed to. II 4-6 dispel possible doubts about the results obtained in II 3 . 
concerns in these chapters and thereby provide an answer to the first question I raised at the start. In order to do this, I shall first sketch the way in which aiming at a definition and producing deductions are linked to each other in what Aristotle may regard as traditional dialectical exchanges (such as, e.g., the discussion about the definition of the sophist in Plato's Sophist). With reference to this background I shall then submit a few considerations about three related points: 1) there are some ambiguities as to whether definition, deduction and demonstration are supposed to be taken as formal objects or as processes which have the explicit formulation of those formal objects as their outcomes; 2) Aristotle seems to entertain the possibility that more than one thing is said or made clear through one and the same statement or through one and the same process - more precisely: the possibility that the definition or demonstration of X makes clear something distinct from X itself; 3) some of the difficulties in understanding what the $\alpha v \alpha \gamma \omega \gamma \eta$ n mentioned in (b) in the opening lines of II 3 is can be set up more clearly with reference to some of the distinctions I made in the course of the paper.

As is well known, $A P o$ II 5 and 6 refer to a (at the time) well-known procedure to obtain definitions by division and to a codified procedure to test definitions (possibly obtained by using the first procedure and in any case displaying the same formal structure of genus and differentiae ${ }^{26}$ ). In both these procedures, deducing and defining were intertwined and might have been regarded as two aspects of one and the same process. In particular, one interesting feature of the Topics is that it is presented as a treatise ideally enabling its users to come up with sullogismoi in support of any claim and that, at the same time, the whole method can be regarded as

${ }^{26}$ It is clear that the Topics take definitions to be composite types of predicate made of genus and differentiae. See e.g. Top. VI 1, 139a27-31. 
definition-oriented ${ }^{27}$. In other words, the Topics testify, among other things, to a context in which deductive arguments are analysed and codified with reference to their contribution to establishing or removing a definition. Within this picture, the process of defining, the process of establishing or supporting a definition through a deductive argument, and the process of deducing a definition may not be clearly set apart.

Two aspects of this picture seem particularly important to trace the background of II 3-7. Firstly, the intertwining of deductive practice and focus on definition does not emerge so much in the structure of definition and deduction understood as given formal objects (a definition as a proposition of a certain type; a deduction as a set of propositions in which one, i.e. the conclusion, follows from necessity from the others, i.e. the premises ${ }^{28}$. Rather, the intertwining emerges if one thinks of the processes of defining and deducing which are involved in the complex argumentative procedure which consists in deriving a definition from a series of dihairetic steps or in establishing a definition through a deduction of a certain type. I do not mean to claim that Aristotle draws a sharp distinction between these two understandings of definition and demonstration, but there are at least some passages which make more sense if one thinks in terms of processes. For example, in II 3, $90 \mathrm{~b} 16$ the definition is said to be the "making known" (gnörismos) of the substance of something; at 90b38, the claim that showing (deixai) the what-it-is and showing that something is (or that something is the case) are different seems to refer to processes of enquiry. In II 5

${ }^{27}$ For this twofold characterisation of the dialectical method see e.g. Top. I 1, 100a18-21 and Top. I 6, 102b27-103a5.

${ }^{28}$ By saying this I by no means intend to exclude that there are contexts in which Aristotle actually talks about definition and demonstration as formal objects. See, for example, (b3), below. 
91b32-36 and 92a3-5 it is not fully clear whether the logos by division Aristotle is talking about is the formulation of the whole dihairetic process or the formula expressing the result of the division. The emphasis in II 7 on what the definer can or cannot "do" in order to show the what-it-is suggests that Aristotle is interested in the procedure which is involved in making a progress in knowledge, more specifically in the knowledge of the what-it-is of something.

Secondly, Aristotle might think that it is possible to "show" more than one thing through one and the same process of defining or of demonstrating - possibly in a different way. In order to make room for this idea, let me recall that a relatively recurrent theme in the Topics is that some things can be "signified in addition" to what is explicitly stated or that, by saying one thing, one automatically says "many things". Examples of the first case are those in which the modality of the belonging of the predicate to the subject is made clear (in addition to the simple belonging of the predicate to the subject) by the way in which the predication is phrased: for example, if someone says that white is coloured, the formulation makes clear that she is saying that colour is an accident of the white (which is wrong, since colour is the genus of the white); if she says that white is a colour, the formulation makes clear that she is ascribing colour to the white as its genus (Top. II 3, 109a23; cf. Top. VII 5, 155a33). Examples of the second case are all claims that follow from a claim explicitly admitted: e.g. if one gives a definition of one of two contrary, the definition of the other contrary will be "signified in addition" (Top. VI 2, 140a19-20: prossemainousin); more generally, if, for example, someone says that something is a man, she has also said that it is an animal and biped and so on (Top. II 5, 112a16-23).

It seems to me that one possibly more complex version of this situation plays some role in II 3-7. As I mentioned earlier, Aristotle might be interested in disentangling two issues: one issue is what a definition (or a demonstration) is 
a definition (or a demonstration) of strictly speaking; the other issue is whether there is anything (and, if so, what) which becomes clear or manifest in producing a definition or a demonstration without being that of which the definition or the demonstration is strictly speaking. That this sort of consideration is somewhere in the background of the discussion in II 3-7 is quite plausible given the occurrence of prosdèloun ("to make manifest in addition to") in II 7, 92b23 and b3429. As for the first issue, Aristotle's idea is (roughly) the following: the definition of $\mathrm{S}$ makes known or plain what $\mathrm{S}$ is; the demonstration of $\mathrm{P}$ makes plain that $\mathrm{P}$ belongs to a certain subject $\mathrm{X}$ by displaying the cause of P's belonging to $\mathrm{X}$. Having scientific understanding of a definable object is having a definition of it, i.e. an account that tells us what that object is; correspondingly, having scientific understanding of a demonstrable object is having a demonstration of it, i.e. a deductive argument accounting for the cause of that object's belonging to a certain subject. There are, however, aspects which in a way have to be ascertained and have to become clear in order to come to know that a certain predicate D expresses the what-it-is of $\mathrm{S}$ : if $\mathrm{D}$ is a composite expression (as it is typically the case with definitions), it must nonetheless refer to something which is essentially one and not an incidental compound; it is not enough that $\mathrm{D}$ belongs to $\mathrm{S}$, but $\mathrm{D}$ must belong to $\mathrm{S}$ in the specific modality of belonging of the what-it-is; finally, $\mathrm{S}$ must exist (since nonexisting objects do not have essences). If these things are supposed to become clear through a demonstration, what

${ }^{29}$ In the first passage the verb is used to claim that a definition "does not make manifest in addition" that what is said is possible or that it is a definition of the subject of which it is supposed to be a definition, since there is always room for asking a question about why this is the case; in the second passage there is no reference to a further enquiry into what is not made manifest in addition by the definition. 
will be the relation between the demonstration(s) of each of these features and the definition to which they are linked? The issue is far from trivial, but it looks like a plausible way to approach it would be by saying that features or conditions of a definition become clear or are shown or are made manifest through demonstrations or, more generally, deductions, which, however, are not of the what-it-is strictly speaking. In fact, this seems to be the way Aristotle will go in the following chapters. However, it should be clear by now that the problems Aristotle faces are deeply enrooted in the whole discussion of II 3-7, which turns out to be much more interesting and much more challenging than is usually acknowledged.

Based on these considerations and to conclude, I would like to submit a few thoughts about the $\dot{\alpha} v \alpha \gamma \omega \gamma \eta$ which appears in (b) at the beginning of II 3 . There are at least three ways in which one can make sense of it.

(b1) The original and literal meaning of $\dot{\alpha} v \alpha \gamma \omega \gamma \eta$ is "bringing up to the surface". If we think that this is what $\dot{\alpha} v \alpha \gamma \omega \gamma \eta$ in (b) means, this interpretation implies a departure from the more technical usages of $\dot{\alpha} v \alpha \gamma \omega \gamma \eta$ which are usually referred to by interpreters, who tend to understand (b) in terms of reduction (of something to be specified) to syllogistic form ${ }^{30}$. On reading (b1), the question in (b) would then be: how is the what-it-is brought up to the surface? In other words, (b) would be an alternative formulation of (a) understood in the way I propose above. I am not sure how appealing this option is, but I do not think that it can be excluded.

(b2) The second possibility is that of taking $\alpha v \alpha \gamma \omega \gamma \eta$ in some technical sense along the lines of the reduction of various arguments to standard syllogisms in $A P r$. It is certainly possible that some reduction to standard syllogistic

${ }^{30}$ See (b2) for further details. 
form is what Aristotle has in mind here too (in particular in II 3, $90 \mathrm{~b} 4 \mathrm{ff}$. and II 4) ${ }^{31}$. Furthermore, it is important to recall that in some cases (such as the reduction of reductio ad impossibilem and, presumably, of other types of reasoning such as induction and example in $A P r$ II 23-24) Aristotle speaks of reduction to syllogistic form of non-syllogistic arguments only to indicate that those arguments include a standard syllogistic part or component, even if there might well be inferential steps within the overall argument which cannot be reduced to syllogistic form. This looser and yet technical sense of reduction might help if one wants to read II 5-6 under the rubric of the reduction announced in (b).

However, deciding in favour of a technical understanding of $\dot{\alpha} v \alpha \gamma \omega \gamma \eta \dot{~ d o e s ~ n o t ~ r e a l l y ~ t a k e ~ u s ~ v e r y ~ f a r, ~ s i n c e ~ i t ~ i s ~ n o t ~}$ clear what the object of the reduction is supposed to be. What is supposed to be reduced to syllogistic form? If the answer is: the definition, then we might have a problem ${ }^{32}$. In particular, in $A P r$ Aristotle talks about a reduction to first syllogistic figure as the procedure consisting in finding the adequate syllogistic premises for a certain conclusion starting from some given premises which are not premises for a first figure syllogism. So, although a reduction is after all a method to find the adequate premises for a given conclusion, it looks like one should start with other premises for that very same conclusion, i.e. with an argument which is not a syllogism in the first figure.

The problem is that, if by "definition" we understand a definitory formula, this is, at best, a proposition of the form "S is $\mathrm{P}$ " (in which $\mathrm{S}$ is a placeholder for the definiendum and $\mathrm{P}$ is a placeholder for the definiens: e.g. 'Human being is rational

31 Cf. fn. 7.

32 If the answer is: The what-it-is, i.e. the object of the definition, we have a problem too. On the possibility of taking the what-it-is as the subject of the "reduction" in a different sense see (b1). 
biped animal') - at worst, just a predicate ('rational biped animal'). With respect to this problem, it is worth stressing that, as I emphasized above, in these chapters Aristotle sometimes seems to talk of the definition (horismos) not so much as a linguistic formula expressing the what-it-is of something, but as the process leading to the identification of the what-it-is and, therefore, to the formulation of the definition. If this is plausible, then the $\alpha v \alpha \gamma \omega \gamma \eta$ mentioned in (b) would amount to something like the Aristotelian syllogistic formulation of the reasoning leading to the formulation of a definition. I do not think this possibility can be simply excluded, but it clearly requires some rethinking of the notion of definition at stake in these chapters.

If, on the other hand, we want to stick with the idea that Aristotle is thinking of some sort of "reduction" of the definition as such (understood as the formula expressing the what-it-is) into an argument, then perhaps we have to allow for a more general sense of $\alpha \dot{v} \alpha \gamma \omega \gamma \eta \dot{~ a s ~ i n d i c a t i n g ~ a ~ p r o c e s s ~}$ of leading back a proposition (in our case: a definition) to a deductive argument - possibly by taking the proposition as the conclusion of the argument ${ }^{33}$.

(b3) The third possibility is rather different. In II 1 and II 2 Aristotle has explained the sense in which all enquiries turn out to be enquiries into a middle term. In particular, enquiring into whether something is and into whether something is the case amount into enquiring into whether there is a middle term; enquiring into what something is and into why something is the case amount to enquiring into what the middle term is. In II 2 Aristotle has put forth the claims that the ti est $i$ is the same as the dia ti (90a9-21) and that knowing the ti esti is the same as knowing the dia ti (90a31-34). The reader is reminded of these results in II 3, 90a35-36, immediately before the passage quoted above.

33 I am grateful to Mauro Mariani for discussion on the issues involved in (b2). 
There are passages ${ }^{34}$ in which $\dot{\alpha} v \alpha \gamma \omega \gamma \eta$ is used to indicate a "reduction" of things or concepts to something more fundamental in virtue of some common structural features. I believe this sense of reduction is relevant in II 3 - in particular, the reduction would amount to explaining how the $t i$ esti is the same as the dia ti, how knowing the ti est $i$ is the same as knowing the dia ti and how both are the same as knowing the middle term. In this sense, Aristotle can say that, in some specific cases, the definition is a sort of demonstration, differing from a demonstration strictly speaking by the disposition and inflection of words (II 10, 94a1-7; 94a11-13). On reading (b3), then, (b) would ask a question (or, at least, would be matched by an answer) about the formal objects definition and demonstration, while (a) would at least include reference to the process of defining (and, indirectly, to the process of demonstrating) ${ }^{35}$.

${ }^{34}$ Detel (Bd. II, 570) provides some references to such passages (Met. IV 2, 1005a1; VI 3, $1027 \mathrm{~b} 14$ ff.; VIII 3, 1044a13), where Aristotle speaks of a reduction of something to something more basic and fundamental, but he does not spell out the nature of such an operation nor does he say whether there are any specific features of the procedure Aristotle suggests in these passages which might be used to make better sense of what goes on in APo II $3 \mathrm{ff}$.

${ }^{35}$ I would like to express my deep gratitude to Lucas Angioni and Breno Zuppolini for their comments on a previous version of the paper and for putting up with a series of delays without making me feel too bad about them. The research in the background of this paper was undertaken during my stay at LMU Munich as a research fellow sponsored by the Deutsche Forschungsgemeinschaft (DFG). 


\section{REFERENCES}

AngIOnI, L. Aristotéles. Segundos Analíticos. Livro II. Tradução, introdução e notas, IFCH/UNICAMP (2nd ed.), 2004.

"Causality and coextensiveness in Aristotle's Posterior Analytics I 13", OSAP, pp. 159-185, 2018.

BARnes, J. Aristotle. Posterior Analytics. Translated with a Commentary, 2nd ed., Clarendon, 1993.

BOlton, R. "Essentialism and Semantic Theory in Aristotle: Posterior Analytics II 7-10", Philosophical Review 85 (4), pp. 514-544, 1976.

"Definition and scientific method in Aristotle's Posterior Analytics and Generation of Animals", in A. Gotthelf \& J. G. Lennox (eds.), Philosophical issues in Aristotle's biology, CUP, 1987.

BronsteIn, D. Aristotle on Knowledge and Learning: The Posterior Anayltics. Oxford, OUP, 2016.

Castelli, L. M. "Alexander on Aristotle An. Pr. I 31, Division and Syllogistic", in Documenti e Studi sulla tradizione filosofica medievale XXVI, pp. 33-54, 2015.

and Rapp, Ch. (in progress), "The logical branch of Aristotle's dialectic. Traces of an early project"

CHARLES, D. Aristotle on Meaning and Essence, Oxford, 2000.

Detel, W. Aristoteles. Analytica Posteriora, 2 Bd., Akademie Verlag, Berlin, 1993.

Devereux, D. \& Demoss, D. "Essence, Existence and Nominal Definition in Aristotle's Posterior Analytics II 8-10", Phronesis 33 (1), pp. 133-154, 1988. 
GAUTHIER, R.-A. (ed.) Sancti Thomae de Aquino expositio libri posteriorum, Roma - Paris, 1989.

McKirahan, R., JR. Principles and Proof. Aristotle's Theory of Demonstrative Science, Princeton University Press, 1992.

MignuCCI, C. Aristotele. Analitici secondi, Laterza, 2007.

Peramatzis, M. "Essence and Per Se Predication in Aristotle's Metaphysics Z4", OSAP 29, 121-182, 2010.

Ross, W. D. (ed.) Aristotle's Prior and Posterior Analytics, Oxford, 1949.

Rossi, P. (ed.) Robertus Grossateste Commentarius in Posteriorum Analyticorum Libros, Firenze, 1981.

WALlies, M. (ed.) Themistii Analyticorum Posteriorum Paraphrasis, CAG V, Berlin, 1900. (ed.) Ioannis Philoponi in Aristotelis analytica Posteriora commentaria cum anonymo in librum II, CAG XIII, Berlin, 1909.

$(\mathrm{cc}) \mathrm{EY}$ 